\title{
MICROANATOMIA E HISTOLOGIA DO SISTEMA DIGESTIVO DE PHYLLOCAULIS SOLEIFORMIS (ORBIGNY) (MOLLUSCA, GASTROPODA, VERONICELLIDAE). V. GLÂNDULA DIGESTIVA
}

\author{
Ana Maria Leal-Zanchet ${ }^{1}$ \\ José Willibaldo Thomé ${ }^{2}$ \\ Josef Hauser $^{3}$
}

\begin{abstract}
MICROANATOMY AND HISTOLOGY OF THE DIGESTIVE SYSTEM OF PHYLLOCAULIS SOLEIFORMIS (ORBIGNY, 1835) (MOLLUSCA, GASTROPODA, VERONICELLIDAE). V. DIGESTIVE GLAND. The digestive gland of Phyllocaulis soleiformis is a compound tubular gland. The secretory tubules are made up of two main cell types: the digestive cells and calcic cells. The digestive cells are the most numerous, usually columnar, and exhibit three different functional stages: absorptive, secretory and excretory. These cells contain two cytoplasmic granules types and, in the excretory stage, most of the cell is occupied by a large vacuole. The calcic cells occur singly or frequently in groups of two or three, are triangular shaped and have distinct apical granules, and yet calcic histochemical detected granules. In addition, there is a third cell type, without characteristic cytoplasmic granules and which correspond to the undifferentiated cells. The excretory ducts system are represented by anterior and posterior vestibules, which branche to form the ducts, that communicate with the secretory tubules. These excretory ducts are lined with a simple epithelium of ciliated columnar cells, followed by a layer of connective tissue with circular and longitudinal muscular fibers. Subepithelial mucous cells are present only in the vestibules.
\end{abstract}

KEY WORDS. Mollusca, Gastropoda, Veronicellidae, Phyllocaulis soleiformis

Este é o quinto e último trabalho de uma série sobre a microanatomia e histologia do sistema digestivo de Phyllocaulis soleiformis (Orbigny, 1835). Os três primeiros referem-se ao tubo digestivo, sendo o primeiro ao esôfago e papo (LEAL-ZANCHET et al., 1989), o segundo ao bulbo bucal (LEAL-ZANCHET et al., no prelo a) e o terceiro ao restante do tubo digestivo (estômago ao reto) (LEAL-ZANCHET et al., no prelo b). O quarto e o quinto trabalhos desta série tratam das glândulas anexas ao tubo digestivo, sendo que o primeiro deles versa sobre a glândula salivar.

1) Instituto de Pesquisas de Planárias, Universidade Vale do Rio dos Sinos, Caixa Postal 275, 93001-970 São Leopoldo, Rio Grande do Sul, Brasil.

2) Instituto de Biociências, Pontifícia Universidade Católica do Rio Grande do Sul, Av. Ipiranga, 6681, 90619-900 Porto Alegre, Rio Grande do Sul, Brasil.

3) Museu de Zoologia, Universidade Vale do Rio dos Sinos, Caixa Postal 275, 93001-970 São Leopoldo, Rio Grande do Sui, Brasil. 
Numerosos trabalhos referem-se à histologia da glândula digestiva dos gastrópodes. Apesar disso, há muitos resultados discordantes quanto à uma constituição histológica e à fisiologia desta glândula. Segundo UMA DEVI $e$ t al. (1981), a glândula digestiva é o local preferencial de infestação por larvas de parasitos helmintos. Por este motivo e também pela sua importância para a compreensão da fisiologia da digestão, torna-se imprescindível o conhecimento da histologia dos tecidos normais, servindo de base para estudos histoquímicos, fisiológicos e patológicos.

Estudos da glândula digestiva dos Veronicellidae são escassos. HOFFMANN (1925) é o primeiro a referir-se à histologia desta glândula em diversas espécies da família. BANI (1961) analisa mais detalhadamente, através de microscopia óptica e eletrônica, a glândula digestiva de Vaginulus borellianus (=P. soleiformis). Em seguida, KULKARNI (1973) analisa as enzimas digestivas presentes na glândula digestiva de Laevicaulis alte.

\section{MATERIAL E MÉTODOS}

O material e métodos aqui utilizados foram descritos em uma publicação prévia (LEAL-ZANCHET et al., 1989).

Devido à rápida deterioração desta glândula, por ocasião da dissecação, tomou-se o cuidado de retirar fragmentos da mesma, tão logo a cavidade geral dos animais tivesse sido aberta. Os fixadores utilizados foram Bouin, Susa, Zenker e Peracchia \& Mittler (LEAL-ZANCHET et al., 1990), sendo que os dois últimos deram melhores resultados.

Foram utilizadas as seguintes colorações: hemalúmen de Mayer e eritrosina (HE), tricrômico de Masson modificado por Goldner (MG), tricrômico de Mallory, método de von Kossa para evidenciação do fosfato de cálcio e a reação histoquímica azul de alcian e ácido periódico/Schiff (AB/PAS).

\section{RESULTADOS}

A glândula digestiva ocupa a maior parte da massa visceral, envolvendo parcialmente o papo, estômago e intestino. É formada por dois lobos, um anterior, maior, cujo ducto desemboca anteriormente na borda esquerda do estômago, e outro posterior que desemboca póstero-ventralmente no estômago. O lobo anterior ramifica-se em vários lóbulos que se espalham e encobrem parcialmente o papo, estômago, intestino tiflossolar e intestino propriamente dito. O lobo posterior possui um formato mais compacto, cônico, sendo que sua porção proximal encobre parcialmente o estômago, enquanto sua porção distal direciona-se posteriormente (LEAL-ZANCHET et al., 1990).

Esta é uma glândula de natureza tubulosa composta, cujos túbulos são formados por uma camada única de células epiteliais, seguida por uma delicada membrana basal e uma fina camada de tecido conjuntivo.

No tecido conjuntivo que ocorre entre os túbulos são principalmente abundantes globulócitos e fibrócitos. Os globulócitos apresentam, além dos 
glóbulos amarelados característicos, grânulos fortemente acidófilos no citoplasma. Frequentemente, estas células formam aglomerados.

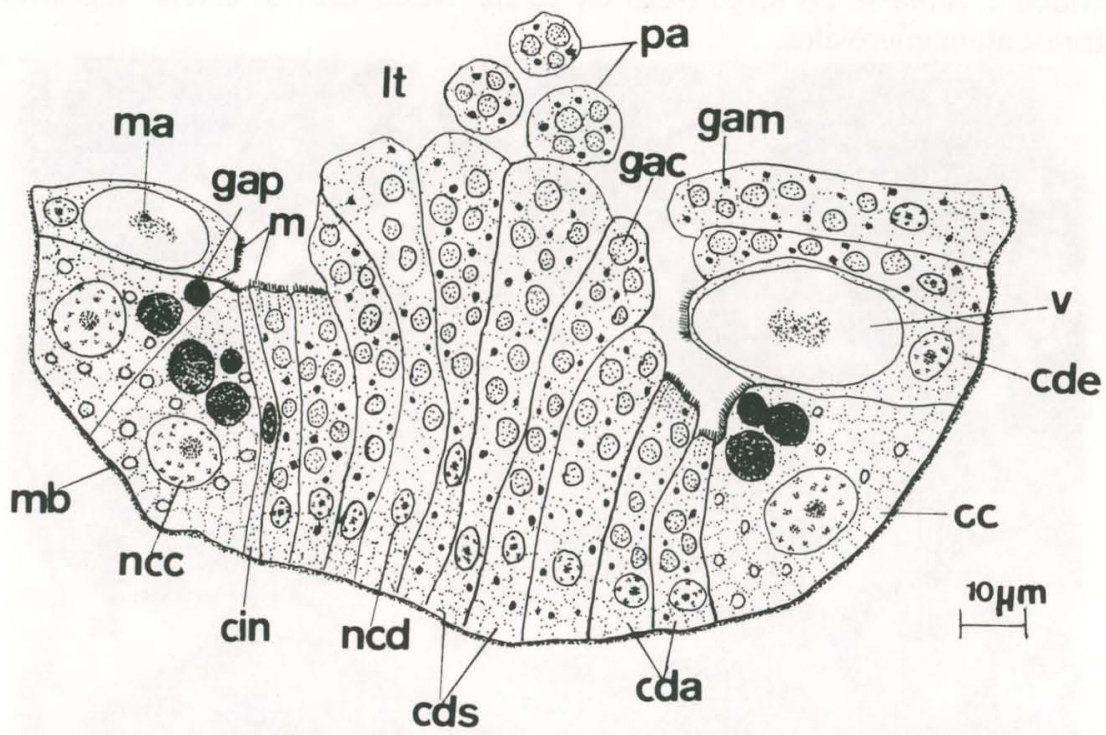

Fig. 1. Detalhe de um túbulo da glândula digestiva. Células calcíferas (cc); célula digestiva (estágio de absorção) (cda); célula digestiva (estágio de excreção) (cde); célula digestiva (estágio de secreção) (cds); célula indiferenciada (cin); grânulos acidófilos (gac); grânulos amarelados (gam); grânulos apicais das células calcíferas (gap); lúmen do túbulo (It); microvilos (m); material amorfo (ma); membrana basal (mb); núcleo de uma célula calcífera (ncc); núcleo de uma célula digestiva (ncd); partes apicais liberados de uma célula digestiva (pa); vacúolo (v).

\section{CÉLULAS SECRETORAS (Figs 1 e 2)}

São identificados dois tipos de células secretoras:

\subsection{Células digestivas}

São as mais numerosas. Exibem formas, dimensões e conteúdos citoplasmáticos variáveis que caracterizam três estágios funcionais diferentes:

a) Estágio de absorção: as células digestivas apresentam-se cilíndricas, relativamente baixas $(31,94 \mu \mathrm{m}$ em média) e estreitas $(8,26 \mu \mathrm{m}$ em média). Possuem um citoplasma acidófilo, contendo dois tipos de granulações: (1) grânulos relativamente grandes $(2,72 \mu \mathrm{m}$ de diâmetro em média), arredondados e ovais, e acidófilos, corando-se em rosa-escuro com HE, verde-claro com MG, azulclaro a azul-esverdeado com Mallory e são positivos ao PAS; (2) grânulos menores $(1,56 \mu \mathrm{m}$ de diâmetro em média), de formato arredondado, oval ou irregular, que são negativos ao AB/PAS e assumem uma coloração amarelada a amarelo-alaranjada com HE, verde-escura brilhante com MG e amareloálaranjada com Mallory. Os dois tipos de grânulos são muito freqüentes no citoplasma supranuclear, mas podem ocorrer também no citoplasma basal. $\mathrm{O}$ 
núcleo destas células é relativamente pequeno $(6,19 \times 5,00 \mu \mathrm{m}$ em média), de formato oval, contendo cromatina granular dispersa no nucleoplasma e nucléolo evidente. Situa-se no terço basal da célula. Nesta fase, as células digestivas apresentam microvilos.



Fig. 2. Secção transversal de um túbulo da glândula digestiva. Coloração: MG. Células calcíferas (cc); célula digestiva absortiva (cda); célula digestiva excretora (cde); célula digestiva secretora (cds); grânulos apicais da célula calcífera (ga); lúmen (I); partes apicais das células digestivas secretoras (pa); vacúolo de uma célula digestiva excretora (v).

b) Estágio de secreção: as células digestivas continuam cilíndricas e estreitas $(8,64 \mu \mathrm{m}$ em média), mas são distintamente altas $(51,66 \mu \mathrm{m}$ em média). os dois tipos de granulações estão presentes e são muito abundantes. Seu núcleo é semelhante ao das células na fase de absorção. Seu ápice é alargado e abaulado, em forma de cúpula, salientando-se no lúmen dos túbulos. Não possui microvilos. Freqüentemente, as partes apicais destas células desprendem-se e são observadas no lúmen dos túbulos (secreção apócrina).

c) Estágio de excreção: possuem um formato oval. Quanto à altura $(33,37 \mu \mathrm{m}$ em média) assemelham-se mais àquelas na fase absortiva, porém são distintamente largas (15,5 $\mu \mathrm{m}$ em média) em relação às fases anteriores. A maior parte destas células é ocupada por um grande vacúolo $(24,00 \times 4,19 \mu \mathrm{m}$ em média), ovalado, que pode conter um material amorfo amarelado ou basófilo (HE), verde-claro (MG) e azul-claro (Mallory). O citoplasma situado lateralmente ao vacúolo é escasso, sendo abundante na parte basal da célula, onde ocorrem raros granulos (semelhantes aos das fases anteriores). O núcleo, situado basalmente, tem aparéncia semelhante aos das células nas fases de absorção e secreção, porém varia de arredondado a oval $(5,62 \times 5,12 \mu \mathrm{m}$ em média). $\mathrm{O}$ ápice celular nesta fase pode mostrar-se abaulado, salientando-se no 
lúmen dos túbulos, ou conter microvilos. O vacúolo, com seu conteúdo, é muitas vezes observado no lúmen dos túbulos.

\subsection{Células calcíferas}

Ocorrem isoladas, ou freqüentemente em grupos de duas ou três, entre as células digestivas. Têm formato em geral triangular, cuja base é mais larga que o ápice. Apresentam uma altura semelhante à das células digestivas nas fases de absorção e excreção (31,10 $\mu$ m em média), mas são muito mais alargadas (29,38 $\mu \mathrm{m}$ em média) do que as células digestivas. Seu citoplasma é levemente esponjoso e basófilo (tende ao roxo) com HE, e contém pequenos grânulos dispersos, que apresentam-se transparentes ou fracamente corados em rosa ou avermelhado (HE, MG e Mallory). Apresentam ainda grandes grânulos apicais de $4,28 \mu \mathrm{m}$ de diâmetro, positivos ao PAS e corados em rosa-escuro (HE), verde (MG) e azul-claro (Mallory). O citoplasma apical acima destes grânulos, apresenta ainda uma fina granulação acidófila. Possuem um grande núcleo $(9,96 x$ $9,58 \mu \mathrm{m}$ em média), basal, de formato circular a oval, com cromatina granular grosseira dispersa pelo nucleoplasma e um grande nucléolo. Grânulos de cálcio de formato circular a oval, histoquimicamente detectados, apresentam um diâmetro de 4,31 $\mu \mathrm{m}$ em média e dispõem-se no citoplasma infranuclear ou logo acima do núcleo destas células.

\subsection{Células indiferenciadas}

Além dos dois tipos celulares principais, ocorrem no epitélio dos túbulos glandulares células muito delgadas (2,42 $\mu \mathrm{m}$ de largura em média), contendo um citoplasma fracamente acidófilo e um núcleo elíptico $(6,50 \times 2,42 \mu \mathrm{m}$ em média), no qual estão dispersos grânulos de cromatina, mas um nucléolo não é visível.

\section{CONDUTOS EXCRETORES}

Os lobos anterior e posterior da glândula digestiva desembocam no estômago através dos vestíbulos.

O vestíbulo anterior da glândula digestiva é constituído por um epitélio cilíndrico simples ciliado, cujas células são mais acidófilas apicalmente e possuem um núcleo oval a elíptico, e por uma camada de tecido conjuntivo que contém células mucosas subepiteliais positivas ao PAS, além de fibras musculares circulares e longitudinais. A parede dorsal deste vestíbulo apresenta dobras longitudinais, enquanto a maior parte da parede ventral é ocupada pela terminação da nervura cárdica. Além das células mucosas subepiteliais do vestíbulo desembocam também no lúmen deste último células secretoras da nervura cárdica (LEAL-ZACHET et al., 1990).

O vestíbulo posterior da glândula digestiva apresenta-se semelhante histologicamente ao vestíbulo anterior, possuindo inclusive células mucosas subepiteliais positivas ao PAS. Difere, no entanto, devido ao fato de que sua parede dorsal é praticamente lisa, enquanto sua parede ventral apresenta dobras longitudinais.

Os vestíbulos ramificam-se e originam os ductos, os quais entram em 
comunicação com os túbulos glandulares. Os ductos são fortemente pregueados, sendo estas pregas formadas principalmente por epitélio, pois é ínfima a quantidadde de tecido conjuntivo que nelas penetra. Células mucosas subepiteliais semelhantes às dos vestíbulos estão ausentes dos ductos. No restante, há apenas uma redução da quantidade de tecido conjuntivo e de fibras musculares em relação aos vestíbulos. Naqueles ductos mais próximos ao vestíbulo anterior ocorrem células secretoras subepiteliais semelhantes às da nervura cárdica.

\section{DISCUSSÃO}

A maioria dos autores denominam este órgão de glândula digestiva, denominação também adotada aqui. RAJALAKSHMI BHANU et al. (1981), BROWN (1969), GUARDABASSI \& FERRERI (1954), VAN WEEL (1949), HOFFMANN (1925) e URBAN (1932) designam-a glândula do intestino médio. PAN (1958), VRIES (1963), CARRIKER \& BILSTAD (1946), MARCUZZI (1950), BAECKER (1932) e BONARDI (1883) chamam-na fígado; enquanto BANI (1961) denomina-a hepatopâncreas.

PAN (1958), RAJALAKSHMI BHANU et al. (1981), BANI (1961), MARCUZZI (1950), BOLOGNANI FANTIN et al. (1982), GABE (1952) e BAECKER (1932) comentam que esta é uma glândula do tipo tubulosa composta. VRIES (1963) e MARTOJA \& THIRIOT-QUIEVREUX (1972) consideram-na uma glândula tubulosa ramificada. Enquanto LUFTY \& DEMIAN (1967) assinalam que esta glândula é do tipo tubulosa composta ramificada. Vários autores, porém, apenas comentam que a glândula digestiva é formada por túbulos (MILLOT, 1937; HOWELLS, 1936; CLELAND, 1954; UMA DEVI et al., 1981; PUGH, 1963; BALAPARAMESWARA RAO, 1975; BEDDINY \& HAMADA, 1982; RUNHAM, 1975; MORTON, 1955a,b; GHOSE, 1963; CARRIKER \& BILSTAD, 1946; BONARDI, 1883; SUMNER, 1965 e VAN WEEL, 1949). Já BROWN (1969) a considera uma glândula acinosa, enquanto GUARDABASSI \& FERRERI (1954) citando BIEDERMANN \& MORITZ (1899) assinalam que esta é uma glândula acinosa composta. E, finalmente, LUFTY et al. (1973) e SALGADO (1983) comentam que esta glândula seria tubulo-acinosa. Concordamos com os primeiros autores, pois constatamos que em $P$. soleiformis a glândula digestiva é de natureza tubulosa composta.

Com relação aos tipos celulares que compõem os túbulos da glândula digestiva, a maioria dos autores consultados (BAECKER, 1932; URBAN, 1932; MARTOJA, 1961; UMA DEVI et al., 1981; PUGH, 1963; RIGBY, 1965; BALAPARAMESWARA RAO, 1975; MORTON, 1955a,b; MARCUZZI, 1950; CARRIKER \& BILSTAD, 1946; BONARDI, 1883; LUFTY \& DEMIAN, 1967; RAJALAKSHMI BHANU et al., 1981 E LUFTY et al., 1973) assinalam a presença de dois tipos de células, com denominações variadas. Apenas RIGBY (1963) e CREEK (1953) consideram que a glândula digestiva tem um único tipo celular. Outros, tais como HOWELLS (1936), CLELAND 
(1954), PAN (1958), BEDDINY \& HAMADA (1982), BOLOGNANI FANTIN et al. (1982), MARTOJA \& THIRIOT-QUIEVREUX (1972), HOFFMANN (1925) e GUARDABASSI \& FERRERI (1954) citando BARFURTH $(1880,1883)$, FRENZEL (1885), BIEDERMANN \& MORITZ (1899), JORDAN (1913) e THIELE (1926), identificaram três tipos celulares. Já GHOSE (1963), GABE (1952), VAN WEEL (1949), SUMNER (1965) e BROWN (1969) descreveram quatro tipos de células para a glândula digestiva. Em $P$. soleiformis foram identificados dois tipos celulares principais: células digestivas e células calcíferas.

As células digestivas de $P$. soleiformis correspondem às células digestivas de CARRIKER \& BILSTAD (1946), PAN (1958), LUFTY et al. (1973), LUFTY \& DEMIAN (1967) e UMA DEVI et al. (1981); células do fermento de BAECKER (1932); células hepáticas de BONARDI (1883); células secretoras-absortivas de URBAN (1932); células absortivas de BALAPARAMESWARA RAO, (1975); células absortivas ou com fermento de MARTOJA (1961); células digestivas e células excretoras de SUMNER (1965), CLELAND (1954), MORTON (1955a,b) e RIGBY (1963, 1965); células absortivas e células de fermento de GUARDABASSI \& FERRERI (1954); células secretoras e células que possuem a propriedade de englobar de BANI (1961); células colunares (CC1 e CC2) de BROWN (1969); células de armazena- mento, células vesiculares e células pseudopodiais de GHOSE (1963); células protéicas ("p-cells"), células com grânulos amarelados ("y-cells") e células com grande vacúolo ("b-cells") de VAN WELL (1949); células eosinófilas de MARCUZZI (1950); células acidófilas de LEAL-ZANCHET et al. (1990); células A de PUGH (1963) e células excretoras de MORTON (1955a,b).

As células calcíferas de $P$. soleiformis correspodem às células excretoras de LUFTY \& DEMIAN (1967), LUFTY et al. (1973), BONARDI (1883), URBAN (1932), BAECKER (1932), BANI (1961), VAN WELL (1949), GHOSE (1963) e GUARDABASSI \& FERRERI (1954); células "calcium" de SUMNER (1965); células calcíferas ("lime") de CARRIKER \& BILSTAD (1946) e PAN (1958); células "calcaire" ou excretoras de MARTOJA (1961); células excretoras de cálcio de UMA DEVI et al. (1981); células secretoras de cálcio de CLELAND (1954); células secretoras de BALAPARAMESWARA RAO (1975); células triangulares de BROWN (1969); células basófilas de MARCUZZI (1950) e LEAL-ZACHET et al. (1990) e células B de PUGH (1963).

Apesar da variada terminologia empregada na literatura, acreditamos que na glândula digestiva dos gastrópodes em geral ocorram dois tipos principais de células. As controvérsias estão relacionadas principalmente com o fato da chamada célula digestiva ser polifásica, como mencionado por CARRIKER \& BILSTAD (1946) e URBAN (1932), ambos citando KRIGJSMAN (1925). De fato, constatamos em $P$. soleiformis, que as células digestivas mostram variações quanto à forma, conteúdo citoplasmático e superfície celular que provavelmente caracterizam três estágios funcionais: secretório, absortivo e excretório. Estágios semelhantes são descritos por BEDDINY \& HAMADA 
(1982) para Bellamya unicolor, CARRIKER \& BILSTAD (1946) para Lymnaea stagnalis apressa e LUFTY et al. (1973) para Bulinus (Bulinus) truncatus. No entanto, BROWN (1969) menciona apenas duas fases destas células para Nassarius obsoletus; assim como BANI (1961) para Vaginulus borellianus ( $=P$. soleiformis). Diferentemente do que verificamos em $P$. soleiformis, RIGBY (1965) para Succinea putris, MORTON $(1955 \mathrm{a}, \mathrm{b})$ para os Ellobiidae e para Otina otis e BANI (1961) para Vaginulus borellianus, consideram as células excretoras (ou células que possuem a propriedade de englobar de BANI, op. cit.) como um tipo celular distinto. Já SUMNER (1965) comenta que as células excretoras corresponderiam a células calcíferas em degeneração. Em $P$. soleiformis, não consideramos as células na fase de excreção como um tipo celular distinto, pois observamos a presença de conteúdos citoplasmáticos semelhantes aos das outras fases da célula digestiva. Além disso, seu núcleo apresenta um tamanho semelhante aos das demais células digestivas. Estes caracteres afastam a possibilidade das células na fase de excreção serem derivadas das células calcíferas, como supunha SUMNER (1965).

A função de secreção das células digestivas, realizada através da liberação de partes apicais (secreção apócrina), observada em $P$. soleiformis é também mencionada por CLELAND (1954) para Valvata piscinalis, UMA DEVI et al. (1981) para Pila virens, RAJALAKSHI BHANU et al. (1981) para Thais bufo, SUMNER (1965) para Helix aspersa e VAN WELL (1950) para Achatina fulica.

Uma atividade absortiva é indicada pelos microvilos presentes na fase absortiva das células digestivas de $P$. soleiformis. Similarmente descreve BROWN (1969), BEDDINY \& HAMADA (1982), LUFTY et al. (1973), SUMNER (1965), MORTON (1955a) e RAJALASKSHMI BHANU et al. (1981). Em P. soleiformis, microvilos foram identificados também nas células calcíferas e em algumas células digestivas no estágio de excreção, o que foi semelhantemente constatado por SUMNER (1965a) para Achatina fulica.

Supõe-se que as células digestivas apresentam ainda uma função excretória por possuírem grandes vacúolos, contendo aparentemente material de refugo, os quais são liberados para o lúmen dos túbulos e são observados também nos cordões fecais de $P$. soleiformis. Esta é também a interpretação de CARRIKER \& BILSTAD (1946), CARRIKER (1946), LUFTY \& DEMIAN (1967), LUFTY et al. (1973) e RIGBY (1963).

As células calcíferas de $P$. soleiformis assemelham-se às suas correspondentes em outros gastrópodes. Sua função é ainda um assunto controvertido. Alguns autores, tais como SUMNER (1965) e MARTOJA (1961), atribuem a estas células uma dupla função: armazenamento de cálcio e secreção de substâncias que atuem na digestão. Armazenamento de cálcio foi comprovado histoquimicamente na espécie em estudo. Julgamos provável que as células calcíferas participem também do processo de digestão.

Além desses dois tipos celulares principais, detectamos em $P$. soleiformis a presença de células muito delgadas e sem inclusôes citoplasmáticas carac- 
terísticas, que devem corresponder a células indiferenciadas. SUMNER (1965), LUFTY \& DEMIAN (1967), LUFTY et al. (1973) e BEDDINY \& HAMADA (1982) mencionam a presença de células semelhantes na glândula digestiva de Helix aspersa, Marisa cornuarietis, Bulinus (Bulinus) truncatus e Bullamya unicolor, respectivamente. A presença de células mucosas nos túbulos da glândula digestiva é descrita em Lymnaea stagnalis apressa por CARRIKER \& BILSTAD (1946), em Australorbis glabratus por PAN (1958) e em Nassarius obsoletus por BROWN (1969). Estas células não foram identificadas nos túbulos da glândula digestiva de $P$. soleiformis.

Com relação aos condutos excretores, células mucosas são descritas para o vestíbulo hepático de Bulinus (Bulinus) truncatus por LUFTY et al. (1973) e de Marisa cornuarietis por LUFTY \& DEMIAN (1967), nos ductos hepáticos de Australorbis glabratus por PAN (1958) e de Achatina fulica por PEREIRA \& BRECKENRIDGE (1981) e VAN WEEL (1949) nos dois condutos coletores principais de Pterotrachea coronata e P. mutica por GABE (1952) nos ductos do fígado dos pulmonados analisados por BAECKER (1932) e nos ductos hepáticos de Lymnaea stagnalis appressa por CARRIKER \& BILSTAD (1946). Contudo estas células mucosas foram descritaš pelos autores como epiteliais, enquanto em $P$. soleiformis foram verificadas células mucosas subepiteliais.

Os ductos da glândula digestiva de $P$. soleiformis têm constituição histológica semelhante a dos vestíbulos (similarmente é descrito por LUFTY \& DEMIAN, 1967 para Marisa cornuarietis), diferindo apenas pelo fato de que a parede dos ductos é mais fina e pregueada e não apresenta células mucosas típicas dos vestíbulos. Esta parede pregueada é característica dos ductos da glândula digestiva dos gastrópodes em geral, sendo descrito pela maioria dos autores.

Constatou-se que os vestíbulos anterior e posterior de $P$. soleiformis diferem entre si em alguns aspectos. Por exemplo, a parede ventral do vestíbulo anterior, que comunica-se com uma projeção da nervura cárdica, é praticamente lisa, enquanto a parede dorsal é pregueada. No vestíbulo posterior, dá-se o contrário. Segundo RIGBY (1963), as diferenças estruturais existentes entre os vestíbulos hepáticos anterior e posterior de alguns gastrópodes são causadas pela sua origem de diferentes componentes do primitivo aparelho de seleção. Em particular, o divertículo anterior seria mais provavelmente derivado do ceco anterior e da área de seleção anterior, visto que ele suporta uma longa crista axial (no caso de $P$. soleiformis, a nervura cárdica) (LEAL-ZANCHET, 1990), que seria parte da, ou certamente comunicaria-se com, a tiflossole maior, como o ceco dos gastrópodes primitivos. $\mathrm{O}$ divertículo posterior seria mais provavelmente derivado da área de seleção posterior.

Como os demais gastrópodes, os ductos e os vestíbulos da glândula digestiva de $P$. soleiformis são ciliados, provavelmente pelo fato das fibras musculares não serem tão abundantes, sendo os cílios responsáveis pelo menos em parte pela movimentação da secreção e/ou do material alimentar. Conforme PEREIRA \& BRECKENRIDGE (1981), os cílios das cristas dos ductos hepáticos direcionam material alimentar para o interior da glândula, enquanto os 
cílios dos sulcos, vibrando na direção oposta, direcionam o material para o estômago. VAN WEEL (1949) menciona que devido à falta de camadas musculares bem definidas ao redor dos túbulos e dos ductos, poderia-se pensar que os cílios são os responsáveis pela saída do material da glândula, mas considera isto improvável, devido ao fluxo de alimento que vem do intestino para a glândula. Comenta que provavelmente os cílios bateriam para dentro, direcionando o material alimentar para a glândula, enquanto a secreção fluiria para o exterior, pelo fato de ser continuamente produzida. Já CARRIKER (1946) acredita que as pulsações da região do estômago, auxiliadas pelas correntes ciliares, seriam responsáveis pelo fluxo de alimento para o interior da glândula. A determinados intervalos, estas pulsações cessariam, e o material de refugo sairia da glândula digestiva. Devido ao estômago de $P$. soleiformis apresentar camadas musculares muito desenvolvidas (LEAL-ZANCHET, 1990), acreditamos que a hipótese de CARRIKER (op. cit.) seja provavelmente verdadeira também para $P$. soleiformis.

\section{REFERÊNCIAS BIBLIOGRÁFICAS}

BAECKER, R. 1932. Die Mikromorphologie von Helix pomatia und einigen anderen Stylommatophora. Z. Gesam Anat., Abt. III, Berlin, 29: 449-585.

BALAPARAMESWARA RAO, M. 1975. Some observations on feeding, anatomy, histology of the digestive tract and digestive enzimes in the limpet Cellana radiata (Born) (Gastropoda: Prosobranchia). Proc. malac. Soc. Lond, London, 41 (4): 309-320.

BANI, G. 1961. Struttura e ultraestruttura dell'epatopancreas di Vaginulus borellianus (Colosi). Monit Zoolo. Ital., Firenze, 69: 157-171.

BEDDINY, E.A.M. \& M.I. HAMADA. 1982. Anatomical and functional studies on the digestive system of Bellamya unicolor (Oliver, 1801). 4. The salivary and digestive glands. Assiut. vet med. J., Assiut, 10 (19): 113-120.

BONARDI, E. 1883. Contribuizione all'istologia del sistema digerente dell' Helix pomatia. Atti della Real Academia delle Scienze, Torino, 19: 33-46.

BOLOGNANI FANTIN, A.M.; L. BOLOGNANI; E. OTTAVIANI \& A. FRANCHINI. 1982. The digestive apparatus of Murex brandaris (L.) and Trunculariopsis trunculus (L.). Zeitschrif mikrosk. anat. Forsch. Leipzig 96 (4): 561-582.

CARRIKER, M.R. 1946. Observations on the functioning of the alimentary system of the snail Lymnaea stagnalis appressa Say. Biol. Bull, Wood Hole, 91: 88-111.

CREEK, G.A. 1953. The morphology of Acmea fusca (Montagu) with special reference to the genital system. Proc. Malac. Soc. Lond., London, 29: 228-240.

GABE, M. 1952. Contribuition a l'étude histologique de l'appareil digestif des Pterotracheidae (Hétéropodes). La Cellule, Louvain, 54: 363-369.

GHOSE, K.C. 1963. The alimentary system of Achatina fulica. Trans. Amer. Microsc. Soc., Menasha, 82: 149-167. 
GUARDABASSI, A. \& E. FERRERI. 1954. Isto-fisiologia dell'aparato digerente di Helix pomatia. Arch. Zool. Ital., Napoli, 38: 61-156.

HOFFMANN, H. 1925. Die Vanginuliden. Ein Beitrag zur Kenntnis ihre Biologie, Anatomie, Systematik, Geographischen Verbreitung und Phylogenie (Fauna et Anatomie Ceylanica, III, Nr. 1). Jena. Zeitschr. Naturwiss. Jena, 61 (1-2): 1-374.

HOWELLS, H.H. 1936. The anatomy and histology of the gut of Cymbulia peroni (BLAINVILLE). Proc. Malac. Soc. London 22 (2): 62-72.

KULKARNI, A.B. 1973. A study on the carbohydrate matabolism in the land slug Laevicaulis alte. Brotéria, Lisboa, 42 (3-4): 111-120.

LEAL-ZANCHET, A.M.; J.W. THOMÉ; J. HAUSER. 1989. Histologia do esôfago e papo de Phyllocaulis soleiformis (Mollusca; Gastropoda; Veronicellidae). Ciên. \& Cul., São Paulo, 41 (10): 1000-1004.

1990a. Histologia da glândula digestiva de Phyllocaulis soleiformis. Resumos do XVII Congresso Brasileiro de Zoologia, Londrina, p.445.

1990b. Microanatomia e histologia do sistema digestivo de Phyllocaulis soleiformis (Orbigny, 1835) (Mollusca: Gastropoda: Veronicellidae) - III. Tubo digestivo (do estômago ao reto). Caatinga, Mossoró, 7: 76-104.

.1991a. Microanatomia e histologia do sistema digestivo de Phyllocaulis soleiformis (Mollusca; Gastropoda; Veronicellidae). II. Bulbo bucal. Acta Biol. Leopold., São Leopoldo, 13 (1): 17-48.

.1991b. Microanatomia e histologia do sistema digestivo de Phyllocaulis soleiformis (Mollusca; Gastropoda; Veronicellidae). IV. Glândula salivar. Comun. Mus. Ciênc. PUCRS, sér. zool., Porto Alegre, 4 (2): 16-27.

LUFTY, R.G. \& E.S. DEMIAN. 1967. The histology of the alimentary system Marisa cornuarietis (Mesogastropoda: Ampullariidae). Malacologia, Ann Arbour, 5: 375-422.

LUFTY, R.; E.S. DEMIAN \& N.H. HAROUN. 1973. The histology of the digestive and salivary glands of Bulinus (Bulinus) truncatus (Audouin). Bull. Zool. Soc. Egypt, Cairo, 25: 75-84.

MARCUZZI, G. 1950. Notas sobre la anatomia y la histologia del caracol Australorbis glabratus (Moll. Gasteropoda). Arch. Venezoelanos Patol. Trop. y Parasit. med. Caracas 2: 1-74.

MARTOJA, M. 1961. Signification fonctionnelle de la glande digestive (hépatopancréas) de Nassa reticulata L. (Mollusque Prosobranche). C. R. Acad. Sci., Paris, 252: 1664-1666.

MARTOJA, M. \& C. THIRIOT-QUIEVREUX. 1972. Particularités histológiques des glandes salivaires et la glande digestive des Atlantidae (prosobranques, Atlantacea: hétéropodes). C. R. Acad. Sci., sér. D., Paris, 275 (12): 1247-1249.

MILLOT, N. 1937. On the morphology of the alimentary canal process of feeding and physiology of digestion of the nudibranch mollusc Jorunna tomentosa (Cuvier). Phil. Trans. R. Soc., ser. B, London, 228: 173-217.

MORTON, J. E. 1955a. The functional morphology of the British 
Ellobiidae (Gastropoda, Pulmonata) with special reference to the digestive and reproductive system. Phil. Trans. R. Soc., ser. B, London, 230: 89-160. 1955b. The functional morphology of Otina otis, a primitive marine pulmonate. Jour. Marine Biol. Ass. U. K., Cambridge, 34: 113-150.

PAN, C.T. 1958. The general histology and topography microanatomy of Australorbis glabratus. Bull. Mus. Comp. Zool., Cambridge, 119 (3): 237-337. PEREIRA, C.R.D. \& W.R. BRECKENRIDGE. 1981. A histolophy- siolocal study of the alimentary system of Achatina fulica (Gastropoda, Pulmonata, Stylommatophora) with particular reference to glands in the tract. Ceylon J. Sci. Biol. Sci., Colombo, 14 (1-2): 152-192.

PUGH, D. 1963. The citology of the digestive and salivary glands of the limpet,

Patella. Quart. J. Micr. Sci., London, 104: 23-37.

RAJALAKSHMI BHANU, R.C.; K. SHYAMASUNDARI \& K. HANUMANTA RAO. 1981a. Studies on the alimentary canal of Thais bufo (Lamark). Histology and histochemistry of foregut and midgut glands. Acta. histochem. Cytochem., Kyoto, 14 (5): 516-523.

RIGBY, J. E. 1963. Alimentary and reproductive systems of Oxychilus cellarius (Müller) (Stylommatophora). Proc. Zool. Soc. Lond., Firenze, 141: 311-359.

- 1965. Succinea putris: a terrestrial opistobranch molusc. Proc. Zool. Soc. London 144: 445-486.

RUNHAM, N.W. 1965. Alimentary canal. In: V. FRETTER \& J. PEAKE (ed.). Functional Anatomy and Physiology. London, Academic Press, vol. 1, 147p. SALGADO, N.C. 1983. Macroanatomia, Microanatomia e Histologia dos sistemas reprodutor e digestivo de Thaumastus (Thaumastus) taunaisi (FÉRUSSAC, 1822), T. (T.) achilles (PFEIFFER, 1852) (Mollusca, Gastropoda, Stylommatophora, Megalobulimidae). Tese de Mestrado, não publicada, Universidade Federal do Rio de Janeiro, Rio de Janeiro, 83p.

SUMNER, A.T. 1965. The citology and histochemistry of the digestive gland cells of Helix. Quart. J. Micr. Sci., London, 106: 173-192.

UMA DEVI, C.; K. HANUMANTHA RAO \& K. SHYAMASUN- DARY. 1981. Observations on the histology and cytochemistry of the digestive gland in Pira virens (Lamarck) (Mollusca: Gastropoda). Proc. Indian Acad. Sci., Anin. Sci, Bangalore, 90 (3): 307-314.

URBAN, E. 1932. Das Darmsystem von Pomatias. Jena. Zeitschr. Naturwiss., Jena, 66: 323-394.

VAN WEEL, P.B. 1950. Contribution to the physiology of the glandula media intestini of the african giant snail, Achatina fulica Fér., during the first hours of digestion. Physiol. Comp. Oecol., Den Haag, 2: 1-19.

VRIES, J.B. 1963. Contribution to the morphology and histology of the nudibranch Melibe rosea Rang. Ann. Universiteit Stellenbosch, Stellenbosch, 38A (1-7): 105-153. 